\title{
The Type of Culture at a High Performance Schools and Low Performance School in the State of Kedah
}

\author{
Yaakob Daud ${ }^{1}$, Arumugam Raman ${ }^{1}$, Yahya Don ${ }^{1}$, Mohd Sofian O. F. ${ }^{1} \&$ Fauzi Hussin ${ }^{1}$ \\ ${ }^{1}$ School of Education and Modern Languages, Universiti Utara Malaysia, Sintok, Kedah, Malaysia \\ Correspondence: Yaakob Daud, School of Education and Modern Languages, Universiti Utara Malaysia, Sintok, \\ 09000 Kedah, Malaysia. Tel: 604-928-5452. E-mail: yaakob@uum.edu.my
}

Received: October 11, 2014 Accepted: November 12, 2014 Online Published: January 27, 2015

doi:10.5539/ies.v8n2p21

URL: http://dx.doi.org/10.5539/ies.v8n2p21

\begin{abstract}
This research aims to identify the type of culture at a High Performance School (HPS) and Low Performance School (LPS) in the state of Kedah. The research instrument used to measure the type of organizational culture was adapted from Organizational Culture Assessment Instrument (Cameron \& Quinn, 2006) based on Competing Values Framework Quinn and Rohrbaugh (1983) Model. Two HPSs and two LPSs representing 129 teachers were chosen as research samples. Research findings showed that the current dominant culture in both HPS and LPS is Hierarchy $(\mathrm{M}=36.76, \mathrm{M}=30.63 \& \mathrm{SD}=8.23, \mathrm{SD}=7.83)$ consecutively. Both types of schools practice Market culture and the average scores for both types of schools are the same whereby HPS (M=25.7, $\mathrm{SD}=8.56)$ and LPS $(\mathrm{M}=25.94, \mathrm{SD}=8.32)$. However, HPS practices less Clan culture $(\mathrm{M}=21.15, \mathrm{SD}=8.74)$ compared to LPS $(\mathrm{M}=24.18, \mathrm{SD}=6.97)$. The Clan culture is more prominent in LPS compared to HPS. Both types of schools practice Adhocracy less which are $(M=17.75, \mathrm{SD}=6.94)$ in HPS and $(\mathrm{M}=19.81, \mathrm{SD}=6.78)$ in LPS respectively. The findings showed that teachers in both types of schools would like to have the Clan culture practiced in their schools with the same average scores, $\mathrm{M}=34.89, \mathrm{SD}=8.22$. HPS prefers the Market culture $(\mathrm{M}=26.01, \mathrm{SD}=6.32)$ compared to LPS Market culture $(\mathrm{M}=23.01, \mathrm{SD}=.22)$. However they accepted Adhocracy less in HPS $(\mathrm{M}=20.02, \mathrm{SD}=8.31)$ and LPS $(\mathrm{M}=21.58, \mathrm{SD}=7.89)$. Nevertheless, Hierarchy culture in HPS $(\mathrm{M}=19.32, \mathrm{SD}=6.45)$ and in LPS $(\mathrm{M}=21.05, \mathrm{SD}=6.68)$ are widely practiced. From the comparisons made, it can be concluded that both types of schools widely practice the Hierarchy and Market cultures in schools. The recommendations for further studies were also suggested.
\end{abstract}

Keywords: school culture, high performance school, low performance school

\section{Introduction}

School performance is related closely to organizational culture practiced in a school. School culture plays a role in driving the school administration towards achieving the goal set by the school (Seshore, 2009). Organizational culture of a school also influences the working culture of the school community and the academic achievements of students. Organizational culture can be defined as a value system whereby members of an organization follow the same organizational culture even though they are from different backgrounds and at different levels in the organization (Robbins \& Sanghi, 2007). Majority of the community in HPS uphold and practice strong beliefs and values of the organization.

The Malaysian system of Education is faced with multitude of issues which affect the effort to improve the quality of education. The Kedah Education State Department (2010) has identified several main issues which influence the state education achievement, among others, are administration and management issues of educational organizations. As a unit responsible in organizing and managing an organization, the school administration should be vigilant and always seek for new strategies to improve performance and service qualities (Marzono, Water, \& McNulty, 2005). Thus, the school administration must have the tenacity and resilience to overcome all kinds of pressure and challenges. Therefore, failure of the administration to make decisions and take appropriate actions will affect the credibility of the whole education system because the society always have high expectations of schools.

School leadership is also responsible for students' achievements. There are still principals and head teachers who fail in practicing instructional leadership which lead to the quality of the education achievement being compromised at the state level. Furthermore, school leadership plays a very important role in the formation and 
maintaining positive organizational culture in schools. Practising positive school culture will contribute to healthy environment and hence improve school performance. Therefore, this research is geared towards studying organizational culture practices in HPS which is a model school and become a benchmark of high standard in order to compete at an international level.

\section{Theoretical Framework}

Research in organizational cultural practices in primary level HPS and LPS in Kedah is developed based on Competing Value Framework Model (CVF) developed by Quinn and Rohrbaugh (1983). The conceptual framework was developed based on research objectives and questions. The instrument used in this research is Organizational Culture Assessment Instrument (OCAI) which was also developed by Cameron and Quinn (1999, 2006). There are four types of culture highlighted in this model which are Clan, Adhocracy, Market and Hierarchy. This research focused on 6 cultural dimensions, namely main features, organizational leadership, employee management, organizational bonding, strategic emphasis and success criteria.

The CVF model is an organization model that is very influential and is widely used in the field of organizational research (Tianyuan, 2009). Compared to other organization models, CVF and the instrument used in this model which is the OCAI has high validity and reliability values. There are four types of organizational cultures in this model which are the Clan, Adhocracy, Market and Hierarchy (Cameron \& Quinn, 2006) cultures. There is a vast difference between these four organizational cultures. The left side of this framework graph shows that the organization is more internally focussed while the right side represents external focus. The top part of the graph represents flexible and free organization while the bottom part represents organization that is stable and under control. Four types of culture which are categorised in the CVF model are Clan, Adhocracy, Market and Hierarchy cultures.

The organizations that practice the Clan culture share a lot of private information and resemble a big family whereby the leaders in the organization are seen as advisers, facilitators and team builders. They are united through loyalty or tradition and the commitment of the members towards the organizations is high. The organizations also emphasize long term benefits in human resource management and organizational success is defined as sensitivity towards customers and care for other people. Adhocracy culture emphasizes output production that is innovative and implements transformation. The organization displays a dynamic and creative place. Members of the organization are ready to take risks and its leadership has high innovative visions. This organization is focused on growth and needs new resources. The organizational success is defined as success in obtaining new and unique products or services.

Market culture emphasizes on perfection in completing any tasks. Members of organizations are competitive in achieving goals. The organizations that practice this culture put much emphasis on winning. They are concerned with reputation and success in achieving goals and targets. Hierarchy culture is a formal and structured organisation where maintaining smoothness of organisations is the priority. Formal rules and policies in many ways unite the organisation. Success is defined by smooth scheduling, task implementation which is under control and low cost human resource management which emphasizes job guarantees. Based on CVF, Cameron and Quinn $(1999,2006)$ has developed a measurement scale that is approriate which is OCAI (Tianyuan, 2009).

\subsection{Research Problems}

Corporate culture and organizational achievement are closely related. The achievement of any organization is largely influenced by the culture practiced in that particular organization. Culture is a value and belief that are shared together to achieve organizational goals. If the culture can be accepted by all members and they work together to increase the performance of the organization, then the culture practiced in the organization is positive. There have been many studies conducted by researchers on the relationship between organizational culture and organizational achievements. Carroll (2008) has conducted a study on the relationships between organizational culture, human resource management and achievements of firms using the CVF model. The research findings conclude that the type of organizational culture has a significant relationship with employee achievements. Three firms were used to study the organizational achievement while two were for financial achievements. The Clan and Adhocracy culture showed a positive relationship with the achievements in the three firms, while the Market and Hierarchy culture showed a negative relationship with the achievements in the three firms. Clan and Market cultures are found to have relationships between management-workers' achievement and worker management-operational performance. Financial performance has a positive significant relationship with the Adhocracy culture and a negative significant relationship with the Hierarchy culture. There are proof that financial performance is indirectly influenced by the relationship between Clan and Market cultures with workers' performance. 
On the other hand, research discussion conducted by Gomez et al. (2011) concluded that their research findings contribute to the understanding of educational process and performance at the secondary level. The research findings suppport the model developed by Heck and Harlinger (1996) regarding the effect of organizational process which includes organizational cultural effects on school performance through teachers in K-8 schools. More over, the findings also identified that the academic achievements of schools and social culture relate positively with students' performance. The research results enhanced the validity and reliability of the research model in reflecting the educational process and achievements in the types of schools mentioned above. The research outcome proved that there is indirect effect of organizational values and climates towards school achievements. There is also direct effects of teachers' behaviour with school achievements. On the whole, the research outcomes provide guidance regarding the components in the organizational culture which requires actions from schools to improve achievements.

\section{Methodology}

\subsection{Research Design}

This is a descriptive survey which used questionaires taken from the OCAI (Cameron \& Quinn, 2006). A set of questionaires was prepared based on cultural dimensions. The four types of cultures which are divided in the CVF model are Clan, Adhocracy, Market and Hierarchy. The questionnaires were distributed to respondents to two HPS and two LPS selected and was administered by the researcher.

\subsection{Population and Sampling}

The research design is based on simple random sampling whereby teachers from HPSs and LPSs in the Kubang Pasu and Kota Setar districts were selected as samples representing teachers' population in Kedah. There are two HPSs in Kubang Pasu District, namely HPS1 consisting of 50 teachers and 79 teachers in HPS2. To represent LPS, a total of 100 primary school teachers from two LPSs in the Kubang Pasu district were selected as research samples. Hence, the total sample of 227 is approriate to represent HPS and LPS teachers in Kedah.

\subsection{Research Instruments}

The research instrument used to study organizational cultural practices in HPS and LPS in Kedah were taken from OCAI (Cameron \& Quinn, 1999, 2006) instrument based on CVF model which was developed for the first time by Quinn and Rohrbaugh (1983). There are four types of culture in the CVF model which are Clan, Adhocracy, Market and Hierarchy. This questionaire consisted of two parts, A and B. Part A required respondents to fill in their personal information. Part B was the section to identify the type of organizational culture based on the six dimensions of culture. The 6 questions were based on perceptions of respondents on current cultural features in their organizations which are organizational leadership, workers' management, organizational bond, strategic emphasis and success criteria. Respondents were also asked to state their expectations on cultural features in their organizations for 5 years to come. Each question has 4 options A,B,C and D. 100 points are divided among the 4 options based on the most accurate alternative answer that reflects the respondent's organization.

\section{Results and Discussions}

Based on the research inquiry the results of the findings are as follows:

What is the cultural practices of HPSs in Kedah?

What is the type of current culture practiced in HPSs in Kedah?

What is the type of culture expected by teachers in HPSs in Kedah in five years to come? 


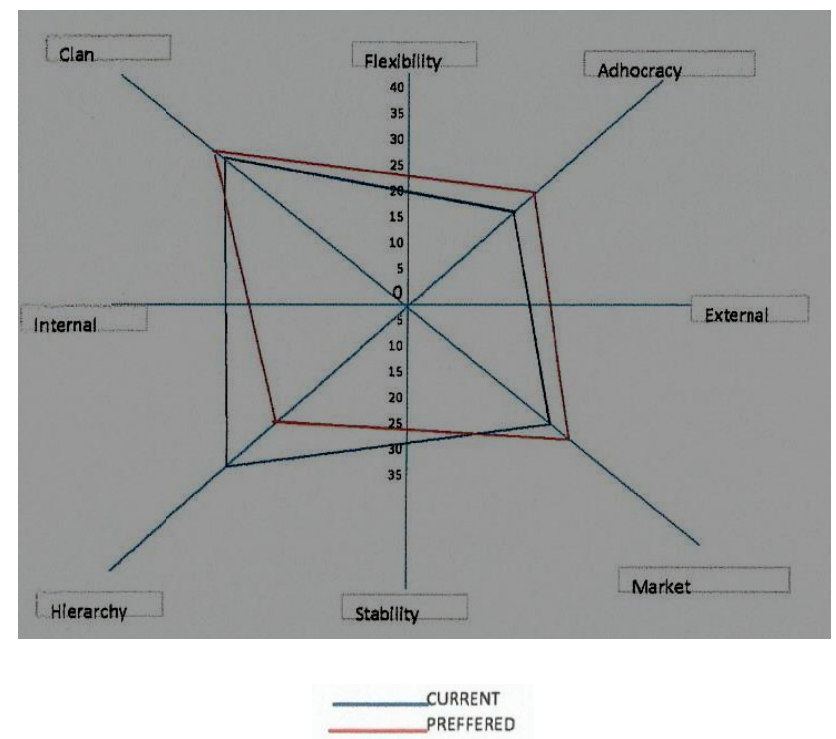

Figure 1. HPS1 organizational culture

Table 1. HPS1 average findings

\begin{tabular}{llll}
\hline Culture & Current & Expectation & Difference \\
\hline CLAN & 28.05 & 29.94 & 1.89 \\
ADHOCRACY & 17.11 & 20.25 & 3.14 \\
MARKET & 23.32 & 26.07 & 2.75 \\
HIERARCHY & 31.9 & 23.29 & -8.61 \\
\hline
\end{tabular}

Figure 1 shows the findings for HPS1. The dominant current culture for this school is Hierarchy $(M=31.9$, $\mathrm{SD}=7.6)$. Whereas Clan $(\mathrm{M}=28.05, \mathrm{SD}=6.44)$ is the second dominant culture in the school. Market $(\mathrm{M}=23.32$, $\mathrm{SD}=6.32)$ and Adhocracy $(\mathrm{M}=17.11, \mathrm{SD}=5.89)$ are two cultures less practiced in HPS. The Hierarchy and Clan cultures can be concluded to be two dominant cultures practiced in the school. This is because of the slight difference between the two cultures which is an average difference of 3.85 .

Interpretation of findings are further expanded by looking at each quarter of the Figure and how the score affects two main dimensions in the plot that are internal focus and integration versus external focus and differences; and flexibility and freedom versus stability and control. The findings show that HPS emphasizes more on internal focus compared to external focus whereby it recognizes the importance of flexibility and freedom and a balance of both stability and control.

The expected culture by the HPS1 teachers in another five years is more dominant towards Clan $(M=29.94$, $\mathrm{SD}=7.32$ ). However, teachers in HPS1 reject Hierarchy culture which is currently widely practiced in the school. The difference in average between current and expected for the Hierarchy culture is 8.61. Even though the results show that the Clan culture is a dominant culture chosen by teachers, the data in the Table 1 shows that the average Clan culture for expectation in HPS1 has decreased compared to the Clan currently being practiced. The finding also shows an increase in Adhocracy $(M=20.25, S D=8.02)$ and Market $(M=26.07, S D=6.50)$ cultures whereby the Market culture is the second highest culture desired by teachers in their schools. The research findings conclude that the teachers' expectations for organization internal focus and external focus are balanced whereby the Clan and Market cultures are the dominant cultures expected by teachers. They also want a flexible and carefree culture but still stable and under control. 


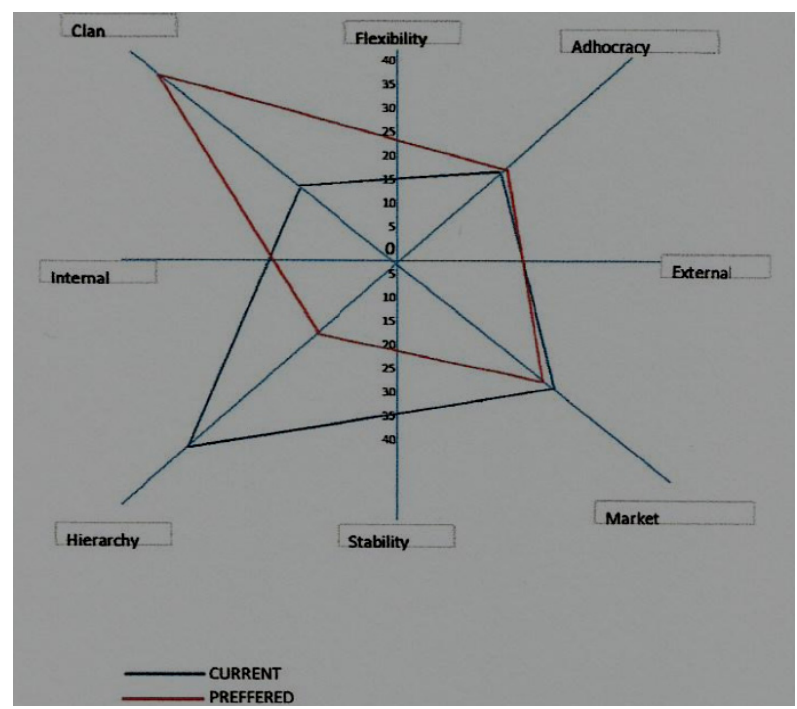

Figure 2. HPS2 organizational culture

Table 2. HPS2 average findings

\begin{tabular}{llll}
\hline Culture & Current & Expectation & Difference \\
\hline CLAN & 16.2 & 38.02 & 21.2 \\
ADHOCRACY & 18.16 & 19.87 & 1.71 \\
MARKET & 27.21 & 25.97 & -1.24 \\
HIERARCHY & 39.83 & 16.81 & -23.02 \\
\hline
\end{tabular}

Figure 2 shows the findings for HPS2. The current dominant culture for this school is Hierarchy $(M=39.83$, $\mathrm{SD}=8.41$ ). Referring to the research findings where the gap between dominant culture and second dominant culture which is Market $(\mathrm{M}=27.21, \mathrm{SD}=6.33)$ is high with a difference in average of 12.62 . Adhocracy culture is the second lowest practiced $(\mathrm{M}=18.16, \mathrm{SD}=6.20)$ whereas Clan culture is the least practiced in the school. The score in the findings shows that Hierarchy and Market are two dominant cultures in HPS2. This also shows that this school practices stability and control in their school in terms of management and leadership. Apart from that, this school emphasizes more on internal focus than external focus. However, they still focus on both dimensions.

The result for HPS2 teachers' expectation on the school culture in five years time is Clan $(\mathrm{M}=27.21, \mathrm{SD}=6.33)$ culture which shows the highest culture chosen by the teachers. The dominant culture practiced currently by the school is the Hierarchy culture which is the lowest culture $(\mathrm{M}=16.81, \mathrm{SD}=5.80)$ expected by teachers for the next five years. This shows that the teachers in HPS2 reject the culture currently practiced in their schools and hope that Clan, the culture currently least practiced in their school will become the dominant culture in the next five years. The Market culture is the second highest culture practiced by the HPS2 teachers is also the second highest culture $(M=25.97, S D=8.11)$ preferred by the teachers. Adhocracy $(M=19.87, S D=6.47)$ will remain less desired by teachers, which is the same situation as the present. However they still want stability and control based on their preference for the Market culture.

What is the cultural practice of LPSs in Kedah?

What is the type of current culture practiced in LPSs in Kedah?

What is the type of culture expected by teachers in LPSs in Kedah in five years to come? 


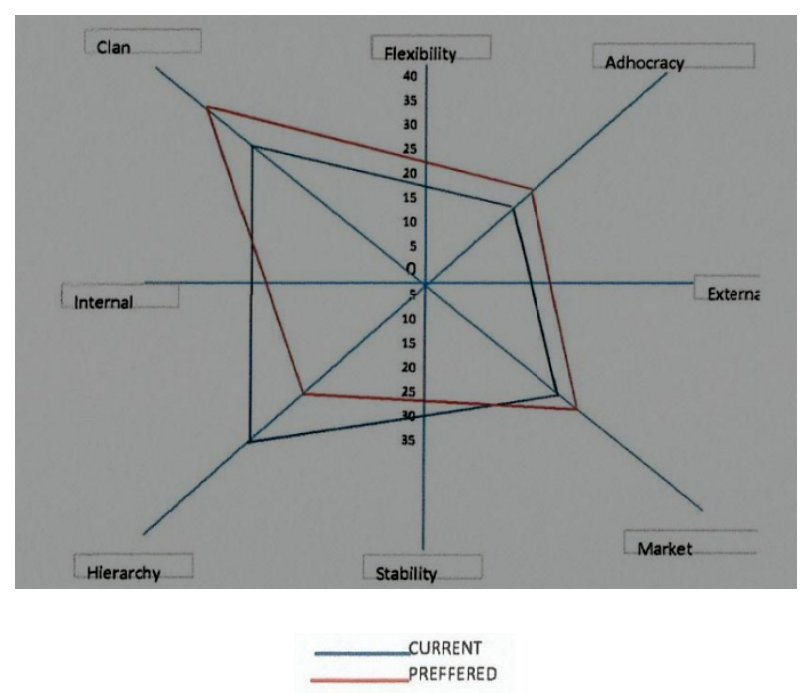

Figure 3. LPS1 Organizational culture

Table 3. Average findings of LPS1

\begin{tabular}{llll}
\hline Culture & Current & Expectation & Difference \\
\hline CLAN & 27.75 & 36.79 & 9.04 \\
ADHOCRACY & 16.58 & 18.04 & 2.46 \\
MARKET & 22.66 & 22.28 & -0.38 \\
HIERARCHY & 33.14 & 23.66 & -9.48 \\
\hline
\end{tabular}

The research results shows (Figure 3) that the Hierarchy $(\mathrm{M}=33.14, \mathrm{SD}=7.96)$ and $\mathrm{Clan}(\mathrm{M}=27.75, \mathrm{SD}=6.51)$ are two dominant cultures practiced in LPS1. The Hierarchy culture obtained the highest score but did not have a significant score difference compared to the Clan with the average difference of 5.39. The Market $(M=22.66$, $\mathrm{SD}=6.08)$ is the third highest culture practiced and Adhocracy $(\mathrm{M}=16.58, \mathrm{SD}=5.79)$ is the least practiced in LPS1. The findings show that the LPS1 prioritizes internal focus in their organizational management and the stability and control dimensions are also practiced and the same goes with flexibility and freedom which are also emphasize in the organization. Findings for the expectation of the LPS1 teachers of the culture in their organizations in another five years show that they prefer the Clan culture $(\mathrm{M}=36.79, \mathrm{SD}=8.18)$ to the Hierarchy culture $(\mathrm{M}=23.66, \mathrm{SD}=6.18)$. The score also shows a high average difference which is 13.13 . The score for the Clan culture is higher than the score for other cultures including Market $(\mathrm{M}=22.28, \mathrm{SD}=6.23)$ and Adhocracy $(\mathrm{M}=19.04, \mathrm{SD}=6.28)$ cultures. The noticeable difference between the Clan culture and other cultures shows that teachers prefer the Clan culture to be the practiced culture in the school. Whereas the other three cultures did not show a noticeable difference. The existing internal focus was also preferred to be maintained and flexibility and freedom are more expected in the organizations compared to stability and control. 


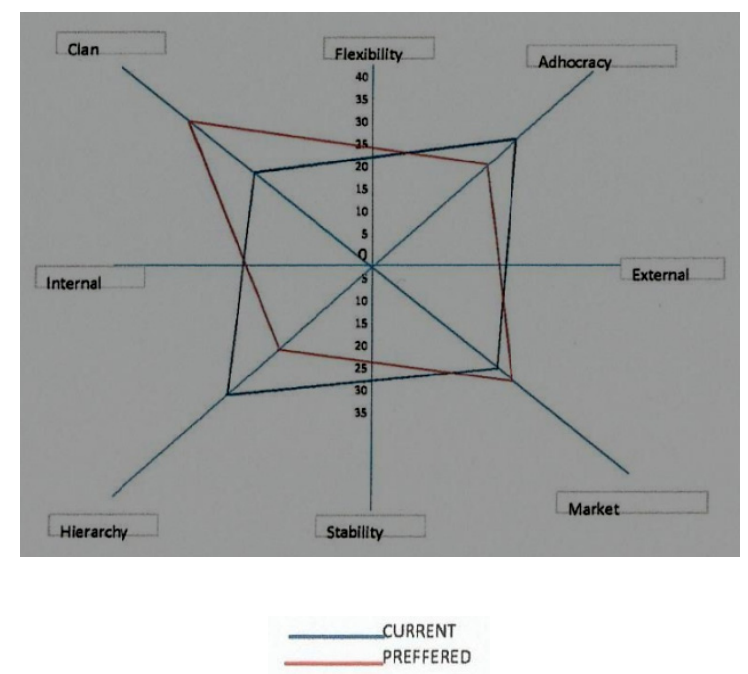

Figure 4. LPS2 organizational culture

Table 4. Average findings of LPS2

\begin{tabular}{llll}
\hline Culture & Current & Expectation & Difference \\
\hline CLAN & 21.33 & 33.37 & 12.04 \\
ADHOCRACY & 28.57 & 23.59 & -4.98 \\
MARKET & 22.66 & 22.28 & -0.38 \\
HIERARCHY & 28.62 & 18.95 & -9.67 \\
\hline
\end{tabular}

Findings for the second type of daily schools, the LPS2 shows that the school does not practice a single dominating culture seeing that data shows that Hierarchy $(M=28.62, S D=6.70)$ and Adhocracy $(M=28.57$, $\mathrm{SD}=6.33$ ) do not have significant score difference, it being only 0.05 . Therefore it can be concluded that LPS2 has two dominant cultures, Hierarchy and Adhocracy. The two lowest cultures, Market $(M=22.66, \mathrm{SD}=5.99)$ and Clan $(\mathrm{M}=21.33, \mathrm{SD}=5.83)$ cultures show insignificant average difference between the two. It can be deduced that both of these cultures are practiced in an equal manner in the school. Even though the Hierarchy culture seem to be the current prevailing one practiced in LPS2 and the Clan culture the least practiced, the data shows that teachers in LPS2 are hopeful that the Clan culture $(\mathrm{M}=33.37, \mathrm{SD}=7.60)$ will be practiced more prevalently in the school and the Hierarchy culture $(\mathrm{M}=18.95, \mathrm{SD}=6.02)$ is reduced. In terms of future expectations, the Adhocracy culture is less preferred by the teachers, noting that there is a marked decrease from the current score $(\mathrm{M}=28.57$, $\mathrm{SD}=6.67)$ to the targeted score one $(\mathrm{M}=23.59, \mathrm{SD}=6.18)$. Nevertheless the targeted score for the Market culture $(\mathrm{M}=22.28, \mathrm{SD}=5.84)$ does not show any significant difference compared to the current score. From the table it can be interpreted that LPS2 has administrative capabilities and is focused in actions both internally and externally. This school is also flexible and free while still maintaining stability and control. Nevertheless data also shows that the teachers in the school expect that the school culture be more flexible and free in nature besides focusing both internally and externally and at the same time putting priority on internal focusing and integration.

Is there a marked difference between the cultures of a HPS with that of LPS in Kedah? 


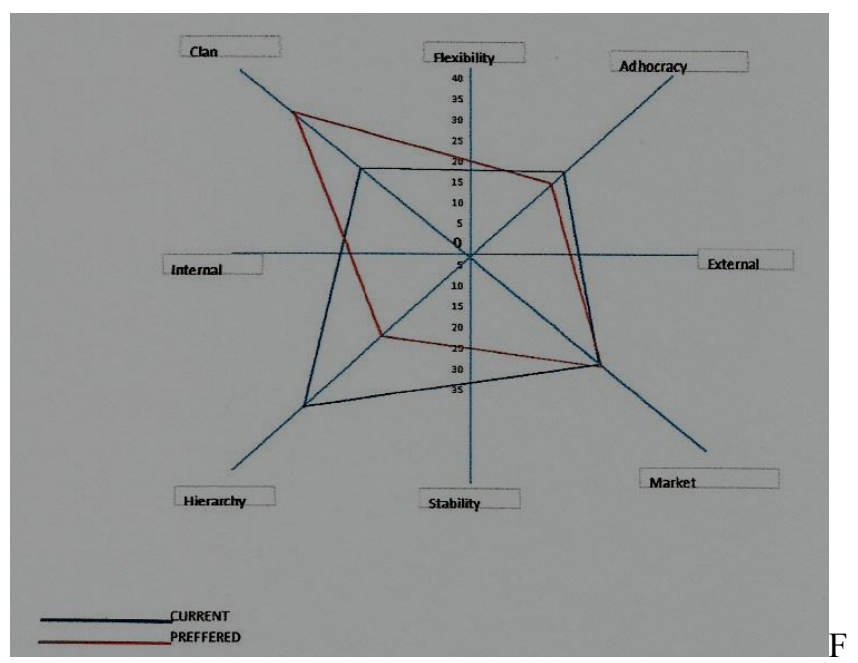

Figure 5. Organizational culture in high performance schools (HPS)

Table 5. Average findings of HPS

\begin{tabular}{llll}
\hline Culture & Current & Expectation & Difference \\
\hline CLAN & 21.15 & 34.89 & 13.74 \\
ADHOCRACY & 17.75 & 20.02 & 2.27 \\
MARKET & 25.7 & 26.01 & 0.31 \\
HIERARCHY & 36.76 & 19.32 & -17.44 \\
\hline
\end{tabular}

The Figure 5 and Table 5 show the results obtained for the combination of two high-performance schools, HPS1 and HPS2. The result clearly shows that HPS practices the culture of Hierarchy $(\mathrm{M}=36.76, \mathrm{SD}=8.23)$. At the same time they also practice the Market culture $(\mathrm{M}=25.7, \mathrm{SD}=8.56)$ as a second dominant culture in their organization. The difference between the two is quite significant, with an average difference of 11.06. Nevertheless, the Clan and Adhocracy cultures are least practiced with the Clan culture $(\mathrm{M}=21.17, \mathrm{SD}=8.74)$ and Adhocracy $(\mathrm{M}=17.75, \mathrm{SD}=6.94)$ culture show a markedly lesser average as compared to the Hierarchy and Market cultures. From this result it clearly shows that HPS focuses in internal integration and also external differences however they stress more on stability and solid control.

If we observe the expectations of the HPS teachers, they are hopeful that the Clan culture $(M=34.89, S D=8.22)$ becomes the dominant culture in their schools. This is proven to be true by the marked difference of the Clan culture as compared to the targeted one with an average difference of 13.72. They are also less receptive to the Hierarchy culture $(\mathrm{M}=19.32, \mathrm{SD}=6.45)$ in their schools. Nevertheless, they still aspire that the Market culture $(\mathrm{M}=26.01, \mathrm{SD}=6.32)$ be kept as the main culture to be practiced in schools. Even though the Adhocracy culture registers the lowest score, data shows that there is an increase from the current score $(\mathrm{M}=17.75, \mathrm{SD}=6.94)$ to the targeted one $(M=20.02, S D=8.31)$. From this result it can also be interpreted that teachers in HPS wish that the organization that they are in prioritizes internal focusing and integration and should be more flexible and free. 


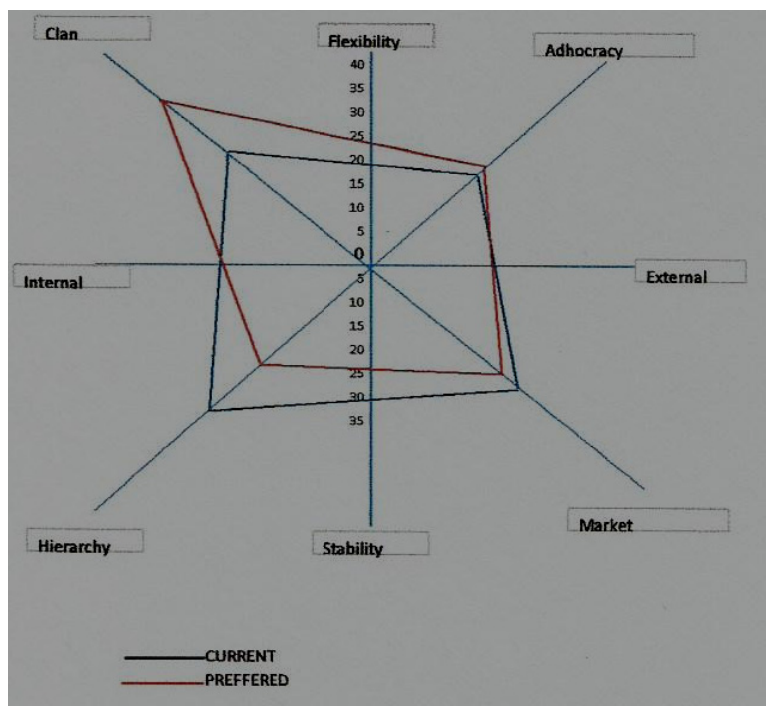

Figure 6. Organizational cultures of low performance schools

Table 6. Average findings of LPS

\begin{tabular}{llll}
\hline Culture & Current & Expectation & Difference \\
\hline CLAN & 24.18 & 34.89 & 10.71 \\
ADHOCRACY & 19.81 & 21.58 & 1.77 \\
MARKET & 25.94 & 23.01 & -2.93 \\
HIERARCHY & 30.63 & 21.05 & -9.58 \\
\hline
\end{tabular}

Questionnaires were distributed in LPS1 and LPS2 to represent the organization of cultures in LPSs in Kedah. The result of the study shows that the Hierarchy culture $(\mathrm{M}=30.63, \mathrm{SD}=7.83)$ is the dominant culture in these schools, while the Market and Clan cultures show a balanced result with the Market culture $(\mathrm{M}=25.94, \mathrm{SD}=8.32)$ and the Clan culture $(\mathrm{M}=24.18, \mathrm{SD}=6.97)$. This shows that both of these cultures are accepted as the second most dominant culture in daily schools. The result also shows that daily schools concentrate on internal focusing and strong integration and stress upon stability and acute control in all organizational processes. In terms of the teachers' expectations in the daily schools, they are more hoping for a Clan culture $(\mathrm{M}=34.89, \mathrm{SD}=8.22)$ to be taken as the dominant culture in their schools. The Market culture $(\mathrm{M}=23.01, \mathrm{SD}=7.22)$ is selected as the second highest culture. The Adhocracy $(\mathrm{M}=21.58, \mathrm{SD}=7.89)$ and Hierarchy $(\mathrm{M}=21.05, \mathrm{SD}=6.68)$ cultures on the other hand mark a balanced average. Daily school teachers are less receptive to the Hierarchy culture practiced currently and many hope that it is the Clan culture that should be stressed more in the future. The result in the expectation section also highlight the wishes of the teachers that the organization should concentrate more on internal focusing and integration and be more flexible and free.

Data shows that the current culture in HPS and LPS is hierarchy. Meaning that both schools can be characterized as a formalized and structured place of work. As a result it is considered predictable and secure. This type of culture is held together by rules and formal regulations. School leaders are good coordinators and organizers. The long-term concerns of the organization are stability, predictability and efficiency. Meeting targets and deadlines are the key to success (Cameron \& Quinn, 2006).

But the most important thing both schools prefer Clan culture. Likewise the Clan organization has less focus on structure and control but greater concern for flexibility. Rather than strict rules and procedures, people are driven through vision, shared goals and outcome which mean that teachers prefer school as an accommodating workplace where people share a lot. It is like a big family. School leaders are treated as mentors who often step into the role of caring parents. Team work and loyalty are principal values. In addition, high levels of loyalty and traditions hold the organization together. Long term personnel development, openness and trust are valued. Sensitivity towards customers is considered as success. In a fast changing educational environment, values should be shared by all teachers in order to operate the school effectively (Cameron \& Quinn, 2006). 
One organizational culture is not necessarily better than the others. The proper culture for each organization depends on the organization's industry and strategy. Gregory, Harris, Armenakis, and Shook (2009) found a positive relationship between clan cultures and patient satisfaction in healthcare facilities. However, a different study (Cameron \& Freeman, 1985) found that organizational effectiveness in institutions of higher education was highest in organizations that emphasized both the adhocracy and hierarchy cultures.

\section{Conclusions}

Overall, organizational culture is a main tool to start and preserve an organization (Fox, 2013). Studies on organizational culture are needed to identify the kind of cultures practiced and can help an organization to manage its culture and manage the change in culture. The instruments used can also become the tool to study the kinds of culture and the relationship between culture and other variables. Results of the studies can also provide clearer understanding on an organization's cultural profile apart from enabling various parties to increase their achievements and quality of the organization towards achieving their objectives. Studies on the cultural organization can also be used as reference for future studies. An organizational culture which is both strong and appropriate with the aspirations of the members in the organization can help preserve excellence in the organization and help in achieving aims and objectives. Apart from that, it becomes the basis for the development of education systems at various levels and helps accomplish basic and realization of government objectives of providing quality education for citizens. It is recommended that schools employ all four dimensions sparingly (i.e., market, clan, adhocracy and hierarchy) in order to enhance school performances.

\section{References}

Ahmad, H., Ahmad, K., \& Shah, I. A. (2010). Relationsip between job satisfaction, job performance attitude towards work and organizational commitment. European Journal of Social Science, 18(2), 257-267.

Cameron, K. S., \& Quinn, R. E. (1999). Diagnosing and changing organizational culture: Based on the competing values framework. Addison-Wesley, Reading, MA.

Cameron, K. S., \& Quinn, R. E. (2006). Diagnosing and changing organizational culture: Based on the competing values framework. San Francisco: Jossey-Bass.

Cameron, K. S., \& Freeman, S. J. (1985). Cultural congruence, strength, and type: Relationships to effectiveness. School of Business Administration, University of Michigan.

Cameron, K. S. (1986). Effectiveness as paradox: Conflict and consensus in conceptions of organizational effectiveness. Management Science, 32, 539-553. http://dx.doi.org/10.1287/mnsc.32.5.539

Carroll, W. R. (2008). Organizational culture, HRM and firm performance: Examining relationship using the competing values framework in call centres (Doctoral dissertation, Saint Mary's University, Halifax, Nova Scotia).

Fox, J. R. (2013). Analyzing the organizational culture of Yolo County using two assessment models (Doctoral dissertation, California State University).

Gomez, M. O., Marcoulides, G. A., \& Heck, R. H. (2012). Examining culture and performance at different middle school level structures. International Journal of Educational Management, 26(2), 205-222. http://dx.doi.org/10.1108/09513541211202004

Gregory, B., Harris, S., Armenakis, A., \& Shook, C. (2009). Organizational culture and effectiveness: A study of values, attitudes, and organizational outcomes. Journal of Business Research, 62(7), 673-679. http://dx.doi.org/10.1016/j.jbusres.2008.05.021

Hallinger, P., \& Heck, R. H. (1996). The principal's role in school effectiveness: An assessment of methodological progress, 1980-1995. International handbook of educational leadership and administration (pp. 723-783). Springer Netherlands. http://dx.doi.org/10.1007/978-94-009-1573-2_22

Kedah State Department. (2010). Statistik Sekolah Negeri Kedah. JPN: Alor Setar.

Malaysia. (2012). Mentransformasi Sistem Pendidikan Malaysia. Program Transformasi Kerajaan 2.0 (GTP2.0). Retrieved from http://www.moe.gov.my

Marzono, R. J., Water, T., \& McNulty. (2005). School leadership that works: From research to results. Alexandria, VA: ASCD.

McLoughlin, P. (2006). Explorinng aspects of organizational culture that facilitate radical product innovation in a small mature company (Doctoral dissertation, Cranfield University). 
Quinn, J. A. (2005). School leadership, culture and teacher stress: Implication for problem students (Doctoral dissertation, Griffith University).

Quinn, R. E., \& Rohrbaugh, J. (1983). A spatial model of effectiveness criteria: Towards a competing values approach to organizational analysis. Management science, 29(3), 363-377. http://dx.doi.org/10.1287/mnsc.29.3.363

Robbins, S. P., \& Sanghi, S. (2007). Organizational Behavior. Pearson Education, New Delhi.

Seshore, K. R. (2009). Leadership and change in school. Journal of Educational Change, 10, $129-140$. http://dx.doi.org/10.1007/s10833-009-9111-4

Tianyuan, Y. (2009). A review of study on the competing values framework. International Journal of Business Management, 4(7).

\section{Copyrights}

Copyright for this article is retained by the author(s), with first publication rights granted to the journal.

This is an open-access article distributed under the terms and conditions of the Creative Commons Attribution license (http://creativecommons.org/licenses/by/3.0/). 